\title{
La visita pastoral de Francisco Fabián y Fuero al obispado de Puebla en 1765
}

\author{
The Pastoral Visitation of Francisco Fabián y Fuero \\ to the Bishopric of Puebla in 1765
}

\author{
Isla Citlalli JIMÉNEZ PÉREZ \\ https://orcid.org/0000-0001-8464-0555 \\ El Colegio de Michoacán (México) \\ Doctorado en Historia \\ citlalli_jimenez94@hotmail.com
}

\section{Resumen}

El presente trabajo tiene como objetivo dar a conocer las actas de la visita pastoral que Francisco Fabián y Fuero, obispo de Puebla de 1765 a 1773, comenzó en 1765 en ciertos curatos de su diócesis. La importancia de este documento radica en que se muestra el gobierno de la diócesis por este influyente prelado, quien es la segunda figura más importante en la escena eclesiástica novohispana de la segunda mitad del siglo XVIII, a pocos meses de haber arribado a la Nueva España. Se ofrecen datos de diversa índole sobre los lugares y la población, además de que hasta el momento este documento está inédito.

Palabras clave: Nueva España; obispado de Puebla; Iglesia católica; gobierno eclesiástico; visita pastoral.

\begin{abstract}
The main objective of this work is to present the acts of the pastoral visit of Francisco Fabian $y$ Fuero, bishop of Puebla from 1765 to 1773, which began in 1765 in certain parishes of his diocese. The importance of this document lies in the fact that it shows how the diocese was governed by this influential prelate, who is the second most important figure in the New Hispanic ecclesiastical scene of the second half of the 18th century, a few months after arriving in New Spain. It offers different information about the places and the population, in addition to the fact that this document is currently unpublished.

Keywords: New Spain; Bishopric of Puebla; Catholic Church; Ecclesiastical government; Pastoral visitation.
\end{abstract}


Las visitas pastorales y su importancia como fuentes

para la historia

En el Concilio de Trento (1545-1563), en la sesión 24, capítulo 3 de Reformatione, se contempló la visita pastoral como un acto de gobierno y de jurisdicción episcopal, estipulando que los obispos debían visitar sus jurisdicciones eclesiásticas por lo menos cada dos años para promover la religión católica y para el buen gobierno de las diócesis. Sólo en el caso de legítimo impedimento, como ausencia o enfermedad, la visita pastoral podría ser llevada a cabo por el vicario general del obispo u otro eclesiástico elegido por él. ${ }^{1}$ También era posible que, en el transcurso de la visita pastoral, el mitrado se encontrase ocupado en algunos asuntos, por lo que designaba a algunos clérigos para efectuar la visita en ciertos puntos de su mitra, mientras él atendía esos pendientes. ${ }^{2}$

Regresando al Concilio de Trento, en él se estipularon los propósitos a que estaba dirigida la visita episcopal, entre los cuales estaban brindar el sacramento de la confirmación - lo cual sólo lo podía hacer el obispo y que se estipuló en la sesión viI del concilio, canon 3 De confirmación-; mantener y conservar la doctrina cristiana; fomentar las buenas costumbres;

${ }^{1}$ En esto sobresale el caso del obispo de Michoacán Pedro Anselmo Sánchez de Tagle de 1758 a 1772, quien por su avanzada edad y enfermedades designó a varios clérigos de su entera confianza en 1764 para realizar la visita pastoral de su diócesis, designándole a cada uno regiones concretas. Éstos fueron Gerónimo López de Llergo, Felipe Vinicio Martínez de Borja, José Manuel de Mafra y José Anastasio Sáenz de Villela. Véase Archivo Histórico Casa de Morelos (en adelante Aнсм), Diocesano, Gobierno, Visitas, caja 500, exp. 50 y 53, f. s/n.

2 Por ejemplo, está Juan Ignacio de la Rocha, obispo de Michoacán de 1777 a 1782, quien designó en plena visita pastoral en 1781, al bachiller don José Domingo Dutari, cura de Zinapécuaro, a quien le tocó visitar la iglesia y la vicaría fija de Otzumatlán, y el bachiller don Luis Mariano de Marticorena, juez eclesiástico del partido de Acámbaro, a quien le fue encomendado visitar el curato de Acámbaro y las ayudas de parroquia de Irámuco, Tarándacuao y Puruagua. Estos clérigos brindarían informes donde tratarían la situación de puntos específicos dictados por el mismo mitrado. El obispo de la Rocha tomó esa decisión ya que se encontraba ocupado en otros asuntos que emergieron durante su visita pastoral. Véase AHCM, Diocesano, Gobierno, Visitas, Informes, 1780, caja 506, exp. 80, f. s/n. También está el caso de otro obispo de Michoacán de 1784 a 1804, fray Antonio de San Miguel, quien nombró sus representantes para visitar algunas zonas de su extensa mitra al entonces juez de testamentos, capellanías y obras pías, el licenciado Manuel Abad y Queipo, y al secretario de Visita el bachiller Santiago Camiña, que también fungía como secretario de Cámara del obispo. Véase Xavier Tavera Alfaro y Juvenal Jaramillo Magaña, Documentos para la historia de la ciudad de Valladolid de Michoacán, v. I (Morelia: LXXI Legislatura del H. Congreso de Michoacán, 2010), 5. 
exhortar a los fieles a la observancia de la religión, a la paz y a la vida cristiana, y a corregir las faltas de los eclesiásticos y todo lo relacionado con su ministerio, por lo que también en las visitas se indagaba sobre la vida y la disciplina del clero, pidiendo a la feligresía denunciar al eclesiástico que hubiera incurrido en alguna falta. Esto último concretamente se abordó en la sesión XIII, sobre Reformatione, capítulo I. ${ }^{3}$

En este sentido, desde su origen tridentino la visita pastoral "no tenía un carácter puramente ceremonioso, sino era esencialmente una rigurosa inspección sobre la vida, costumbres y, en general, la disciplina del clero. Disciplina que debía advertirse, entre otras cosas, en su cuidado y hábitos personales, pero también en el cuidado, decoro y aseo de las cosas de la Iglesia, en el escrupuloso manejo de los archivos, libros y registros de bautizos, casamientos y entierros, y en las listas de cofradías, capellanías, obras pías y hospitales". ${ }^{4}$ Del mismo modo también el obispo revisaba las vigencias de las licencias de confesar, predicar y celebrar de los curas.

Esto fue ratificado por el rey Felipe II ${ }^{5}$ y, en la Nueva España, por el III Concilio Provincial Mexicano de 1585.6 Debido al Real Patronato, los monarcas emitieron diferentes disposiciones que también refrendaban lo dicho en Trento, subrayando el papel de los obispos y de las visitas como medios para el mejoramiento espiritual de la feligresía, una de las principales preocupaciones de la Corona española. ${ }^{7}$

${ }_{3}^{3}$ Tavera Alfaro y Jaramillo Magaña, Documentos para la historia, 9.

${ }^{4}$ Tavera Alfaro y Jaramillo Magaña, Documentos para la historia..., 9-10.

${ }^{5}$ Valentina Garza Martínez y Juan Manuel Pérez Zevallos, Las visitas pastorales de Mazapil, 1572-1856 (México: Centro de Investigaciones y Estudios Superiores en Antropología Social; Mazapil, Zacatecas: Municipio de Mazapil; San Luis Potosí: Archivo Histórico del Estado de San Luis Potosí "Lic. Antonio Rocha Cordero"; México: Editorial Letra Antigua; Zacatecas: Instituto Zacatecano de Cultura “Ramón López Velarde”, 2007), 24-25.

${ }^{6}$ Manuscritos del Concilio Tercero Provincial Mexicano (1585), edición, estudio introductorio, notas, versión paleográfica y traducción de textos latinos por Alberto Carrillo Cázares, primer tomo, v. I (Zamora: El Colegio de Michoacán; México: Universidad Pontificia de México, 2006), 253-264.

${ }^{7}$ Rodolfo Aguirre Salvador, coord., Visitas pastorales del arzobispado de México, 17151722, 2 v., v. I (México: Universidad Nacional Autónoma de México, Instituto de Investigaciones sobre la Universidad y la Educación, 2016), XLII-XLIII. Al respecto considero pertinente mencionar que al momento de estudiar o usar como fuente las actas de visita pastoral, es importante, tal como lo es en cualquier documento histórico, no extraerlo de su contexto ya que en muchas ocasiones éste podría determinar varios factores, incluso la misma vista. Ejemplo de esto es el caso de la visita pastoral efectuada por fray Antonio de San Miguel, obispo de Michoacán de 1784 a 1808, quien decidió llevar a cabo una visita a su diócesis a partir del año 1788 a 1792, motivado en gran parte por las pretensiones del vecino 
Bajo estas directrices, desde el siglo xvi se efectuaron diversas visitas pastorales en las diócesis de la Nueva España. La mayoría de los prelados desearon conocer cada parroquia de su mitra para enterarse de primera mano de las diferentes circunstancias y problemáticas y así darles solución; sin embargo, su avanzada edad, sus enfermedades, sus múltiples ocupaciones, la gran extensión de las demarcaciones eclesiásticas o su sorpresiva muerte, que ocurría en ocasiones en la misma visita, ${ }^{8}$ no siempre hacían esto posible, de ahí que las visitas pastorales varíen en el tiempo, la extensión y los poblados visitados. También es posible que algunos prelados, por alguna de las cuestiones mencionadas líneas arriba, no hayan podido efectuar la visita pastoral, por lo que, aunque esto era un punto inherente a su ministerio, no siempre se podía realizar. Retomando el tema de la extensión de las diócesis, hay que recordar que, para los tres siglos coloniales, los obispados novohispanos se caracterizaron por su extraordinaria extensión, por lo que fueron pocos los obispos que lograron visitar la mayor parte de su diócesis, siendo los más los que visitaron regiones específicas. Por esta gran extensión también era frecuente que la visita pastoral se efectuara por etapas y en varios años, no de corrido. ${ }^{9}$

Durante el trayecto de la visita pastoral, el obispo viajaba con una comitiva que él mismo seleccionaba para que se desempeñaran en diferentes aspectos durante el recorrido, donde destacan los secretarios, quienes

obispado de Guadalajara de hacerse de los curatos de Colima, Zapotlán y La Barca, argumentando ante el rey su estado de abandono espiritual por la lejanía de Valladolid, capital del obispado michoacano. En ese contexto, en esta visita, además de llevar a cabo las labores que tradicionalmente tenían que ver con ésta, se le utilizó como un instrumento para revirar las críticas y acusaciones de las que era objeto la mitra michoacana para evitar perder estos territorios lo que, eventualmente, no se pudo lograr. Véase Tavera Alfaro y Jaramillo Magaña, Documentos para la historia, 536. Juvenal Jaramillo Magaña, Hacia una Iglesia beligerante: la gestión episcopal de fray Antonio de San Miguel en Michoacán (1784-1804). Los proyectos ilustrados y las defensas canónicas (Zamora: El Colegio de Michoacán, 1996), 117-124.

${ }^{8}$ Al respecto está el caso de Luis Fernando de Hoyos y Mier, obispo de Michoacán de 1773 a 1775, quien murió el 13 de diciembre de 1775 mientras efectuaba su visita pastoral en el pueblo de Rincón de Tamayo. Véase Juan B. Buitrón, Apuntes para servir a la historia del arzobispado de Morelia (México: Imprenta Aldina, 1948), 146.

${ }^{9}$ Me refiero, por ejemplo, al caso del arzobispo de México de 1766 a 1772, Francisco Antonio Lorenzana y Buitrón, quien efectuó por distintas etapas la visita pastoral a su arquidiócesis. Este mitrado realizó seis visitas diocesanas en el transcurso de tres años, de 1767 a 1769. Véase Clemente Cruz Peralta, Entre la disciplina eclesiástica y la reforma de las costumbres. Visitas pastorales de Francisco Antonio Lorenzana a la arquidiócesis de México, 1767-1769 (tesis de maestría, Universidad Nacional Autónoma de México, Facultad de Filosofía y Letras, Instituto de Investigaciones Históricas, 2016), 193. 
tenían la obligación de dejar puntual testimonio de todo lo que sucedía, así como expedir diferentes documentos. ${ }^{10}$ Estos testimonios son los que se conocen ahora como asientos o actas de visita. Dependiendo de los objetivos particulares de la visita, en estas actas se asentaba información variada, que va desde las distancias de las parroquias y curatos, el número de habitantes y las calidades, la fábrica material y espiritual, las advocaciones religiosas, las lenguas habladas por la feligresía, si había conventos y cuántos religiosos o religiosas tenían, los eclesiásticos a cargo de la parroquia, si había haciendas o la situación general de la economía local, entre otras. También, y no menos importante, es que en ocasiones en las actas se reproducía literalmente lo mandado o dicho por el obispo, lo que nos acerca más a las posturas de los prelados ante temas concretos. Como mencioné anteriormente, no siempre se visitaba la totalidad del obispado, por lo que la información que algunas de estas actas nos proporcionan es parcial, variando también en su extensión. ${ }^{11}$ Hay unas que son extensas y detalladas y otras son breves, dependiendo del tiempo que dispuso el obispo para efectuar la vista y la ruta seguida.

Es también importante subrayar que la información recabada en las visitas pastorales no servía únicamente a los obispos para conocer el estado de su diócesis, sino que además podía servir al rey. Por la función del patronazgo real, los prelados tenían la obligación de enviar al monarca la información que le fuera solicitada, como un medio de actualización y control. ${ }^{12}$ Seguramente esto ayudó a definir el rumbo de diferentes políticas reales.

${ }^{10}$ Aguirre Salvador, Visitas pastorales, XLVII.

${ }^{11}$ Los curatos y doctrinas que visitaría el obispo quedaban establecidos en la carta cordillera emitida por el prelado, que después se copiaba y se enviaba mediante una carta derrotero a los lugares que estaban incluidos en la visita pastoral. Cada vez que el mitrado establecía una nueva ruta de visita se volvían a emitir estas cartas; esto era muy común en la Nueva España por la extraordinaria extensión de los obispados que impedían que en un recorrido se visitaran todas las parroquias y curatos. Como ejemplo de esto está la visita que realizó el arzobispo de México de 1714 a 1728, José Lanciego y Eguilaz, entre 1715 a 1722, dividida en nueve recorridos y, por ende, emitió nueve cartas cordilleras. Véase Aguirre, Visitas pastorales, XLI-XLIV.

${ }^{12}$ María Guadalupe Cedeño Peguero y Silvia Montes de Oca Mireles, "Visitas episcopales en Michoacán e historia social purépecha”, en Los occidentes de México (siglos XVI-XIX). El archivo, instrumento y vida de la investigación histórica, compilación de Celina Guadalupe Becerra J. (México: Centro de Estudios Mexicanos y Centroamericanos; Guadalajara: Universidad de Guadalajara; Zamora: El Colegio de Michoacán; Zacatecas: Universidad Autónoma de Zacatecas, Doctorado en Historia INAH-UAZ; Morelia: Archivo Histórico del Municipio de Morelia; Zapopan: El Colegio de Jalisco; México: Centro de Investigaciones y Estudios Superiores en Antropología Social, 1997), 150. 
Ya para la segunda mitad del siglo XVIII, en el contexto de reforma eclesiástica, jansenismo e ilustración católica, ${ }^{13}$ se refuerza el carácter de las visitas pastorales como instrumentos de diagnóstico, y, apoyados por ellas, se propiciaron diversos cambios. La mayoría de los obispos que ocuparon una mitra en esa temporalidad comulgaban con estas corrientes de pensamiento; aspiraban a un mejoramiento espiritual y material de la sociedad, además de crear una Iglesia católica que ejerciera un papel activo, que diera soluciones a los problemas sociales, más que permanecer en una postura contemplativa. En este sentido, y no únicamente por los mitrados, se hace una aguda crítica al pasado, se revisan las acciones realizadas $\mathrm{u}$ omitidas, lo que desemboca en desencanto, al ver su presente de contrastes, alejado del progreso. Así, en esta inspección necesaria para el apremiante y urgente cambio, se encuentran las visitas pastorales. Para este momento de la segunda mitad de la centuria dieciochesca, resulta indispensable estudiar las visitas pastorales de los prelados para entender mejor sus políticas y sus posturas ante ciertos temas durante su gestión episcopal. Es decir, las visitas nos brindan la realidad observada por éstos y su perspectiva, la que motivaría ciertas disposiciones en materias concretas.

De este modo, las actas de visita constituyen valiosas fuentes de primera mano para la investigación histórica. Mediante ellas podemos estudiar temas geográficos, sociales, políticos, de historia del arte, eclesiásticos, demográficos, religiosos, económicos, educativos, toponímicos, culturales, entre muchos otros, dependiendo de los objetivos concretos de nuestra investigación.

$\mathrm{Al}$ respecto, podemos decir que en fechas recientes se han incrementado en la historiografía novohispana los estudios de las visitas pastorales; por ejemplo, la obra coordinada por Rodolfo Aguirre titulada Visitas pastorales del arzobispado de México, 1715-1722, en donde se ofrecen dos estudios introductorios y la transcripción íntegra de las visitas pastorales del arzobispo de México, de 1714 a 1728, José Lanciego y Eguilaz. De este mismo prelado, Marco Antonio Pérez Iturbe y Berenise Bravo Rubio escribieron en conjunto

${ }^{13} \mathrm{Al}$ respecto, Clemente Cruz Peralta, quien se dedicó en su tesis de maestría a estudiar las visitas pastorales del arzobispo de México Francisco Antonio Lorenzana y Buitrón, uno de los máximos exponentes de la reforma eclesiástica y la Ilustración católica en la Nueva España, menciona que: “[...] en las visitas pastorales de Lorenzana se reflejó su amplia reforma eclesiástica que estuvo en sintonía con el proyecto de la monarquía de la Casa de Borbón, que pretendía incorporar y reimpulsar una serie de políticas gubernamentales en temas fundamentales como la promoción del idioma castellano, la reorganización de los espacios diocesanos y la secularización eclesiástica”, en Cruz Peralta, Entre la disciplina eclesiástica, 169. 
un estudio titulado "Hacia una geografía espiritual del arzobispado de México, la visita pastoral de José Lanciego y Eguilaz de 1715”, en donde estudian las características generales de dicha visita. Clemente Cruz Peralta se dedicó en su tesis de maestría titulada "Entre la disciplina eclesiástica y la reforma de las costumbres. Visitas pastorales de Francisco Antonio Lorenzana a la arquidiócesis de México, 1767-1769”, a analizar la visita pastoral del arzobispo de México de 1766 a 1771, Francisco Antonio Lorenzana y Buitrón, añadiéndolas completas. En esta línea también se encuentra la obra Las visitas pastorales de Mazapil, 1572-1856, escrita por Valentina Garza Martínez y Juan Manuel Pérez Zevallos, aunque ésta únicamente se centra en tal población. Para el caso del obispado de Michoacán, Juvenal Jaramillo Magaña y Xavier Tavera Alfaro publicaron en 2010 la obra que lleva por nombre Documentos para la historia de la ciudad de Valladolid de Michoacán, 1807-1823, que abarcó tres volúmenes, siendo en el primero de ellos donde se reproduce la visita pastoral que llevó a cabo de 1788 a 1792 el obispo fray Antonio de San Miguel Iglesias, quien fuera obispo de Michoacán de 1784 a 1804, por casi toda la diócesis michoacana, añadiendo previamente un estudio introductorio para entender el contexto de esa visita y su valor como fuente. ${ }^{14}$

Sin embargo, desde mi punto de vista todavía queda mucho por hacer en esta materia. En los archivos nos aguardan estas valiosas fuentes para hacer uso de ellas en nuestras investigaciones o analizarlas en sí mismas. De ahí la importancia de las visitas como una fuente con gran potencial para nuestro trabajo como historiadores por lo cual presento a continuación las actas de visita pastoral de Francisco Fabián y Fuero, obispo de Puebla de 1765 a 1773, a algunos curatos que se localizaban al sur de su diócesis, en los actuales estados de Puebla y Guerrero, y otros situados más al norte, pertenecientes hoy en día al estado de Veracruz. De estos curatos, la información que hallamos en las actas de visita que aquí presentamos es muy variada y nos permite estudiar la cuestión demográfica, ya que se menciona el número de feligreses de cada una de ellas por calidad, el estado de la fábrica material de las iglesias y las advocaciones religiosas a las que estaban

${ }^{14}$ Aguirre Salvador, Visitas pastorales, 1038. Marco Antonio Pérez Iturbe y Berenise Bravo Rubio, "Hacia una geografía espiritual del arzobispado de México, la visita pastoral de José de Lanciego y Eguilaz de 1715”, en Doris Bieñko de Peralta y Berenise Bravo Rubio (coords.), De sendas, brechas y atajos. Contexto y crítica de las fuentes eclesiásticas, siglos XVI-XVIII (México: Escuela Nacional de Antropología e Historia; México: Consejo Nacional para la Cultura y las Artes, 2008), 147-165. Cruz Peralta, Entre la disciplina eclesiástica, 430. Garza, Las visitas pastorales de Mazapil, 609. Tavera Alfaro y Jaramillo Magaña, Documentos para la historia, 536. 
dedicadas cada una de ellas, si había haciendas o la situación económica de estos lugares, el número de clérigos y religiosos, las lenguas de los indios mayormente habladas y, por supuesto, la toponimia.

Además de la gran importancia que tiene el documento per se y los valiosos datos que brinda respecto de las poblaciones de la diócesis poblana antes mencionadas, se le añade que trata de una de las diócesis más importantes de la monarquía española, la segunda más pingüe de las Indias en la segunda mitad del siglo xvin y la primera fundada en la Nueva España. ${ }^{15}$ A esto se le suma la trascendencia de Francisco Fabián y Fuero, quien se convirtió en una figura de gran relevancia para la historia novohispana, por sus ideas y por pertenecer a la corriente de reformismo eclesiástico, modernidad cristiana e Ilustración católica. ${ }^{16}$ Como obispo de Puebla sobresalió su actuación en lo concerniente a la educación y la moralización del clero, la castellanización de los indios, el IV Concilio Provincial Mexicano y el prolongado y difícil conflicto con las monjas calzadas de la diócesis por la imposición de la vida común en los conventos, entre otros. ${ }^{17}$ Desde mi perspectiva, estas actas de visita pastoral que presentamos ayudarán a estudiar mejor la gestión episcopal de Francisco Fabián y Fuero en Puebla, su faceta como visitador de su diócesis, así como aprovechar la información que en estas actas se asentó sobre los poblados visitados.

15 Óscar Mazín Gómez, "Reorganización del clero secular novohispano en la segunda mitad del siglo xviıı”, Relaciones, v. x, n. 39 (1989): 75. Jesús Márquez Carrillo, Política, Iglesia y modernidad en Puebla. Las ideas y proyectos reformistas del obispo Francisco Fabián y Fuero, 1765-1773, primera edición digital (México: Benemérita Universidad Autónoma de Puebla, Facultad de Filosofía y Letras, 2017), 51, http://www.filosofia.buap.mx (consulta: 2 de enero de 2018). Joseph Antonio de Villaseñor y Sánchez, Theatro americano, descripción general de los reynos y provincias de la Nueva España y sus jurisdicciones (México: Trillas, 1992), 54 y 207. Mariano Cuevas, Historia de la Iglesia en México, t. I (México: Imprenta del Asilo "Patricio Sanz", 1921), 294-295.

${ }_{16}$ Jaramillo Magaña, Hacia una Iglesia beligerante, 24.

${ }^{17}$ Márquez Carrillo, Política, Iglesia, 135, 138 y 142. Jesús Márquez Carrillo, “Experiencia interior y política pastoral. El obispo Francisco Fabián y Fuero en Puebla 17651773", Graffylia. Revista de la Facultad de Filosofía y Letras, v. 2 (2003): 10. Elisa Luque Alcaide, "Los concilios provinciales hispanoamericanos", en Teología en América Latina, Volumen II/1, dirección de Josep-Ignasi Saranyana y coordinación de Carmen-José Alejos Grau (Madrid: Iberoamericana; Frankfurt: Vervuert, 2005), 427. Luisa Zahino Peñafort, El cardenal Lorenzana y el IV Concilio Provincial Mexicano (México: Miguel Ángel Porrúa; México: Universidad Nacional Autónoma de México, Instituto de Investigaciones Jurídicas; Ciudad Real: Universidad de Castilla-La Mancha; Ciudad Real: Cortes de Castilla-La Mancha, 1999), 6-7, 338, 345 y 449. 
Para concluir, es importante mencionar que este documento se encuentra físicamente en la Real Biblioteca del Palacio Real de Madrid, en España. ${ }^{18}$ Hasta la fecha este documento no se encuentra digitalizado y, por ende, tampoco está disponible para su consulta en algún portal electrónico, lo que ha imposibilitado que sea trabajado por los investigadores dedicados a este periodo, personaje y/o diócesis, lo que explica que no sea mencionado en las investigaciones. De este modo, estas actas de visita pastoral del obispo Francisco Fabián y Fuero permanecen inéditas, por lo cual consideramos que es muy pertinente su publicación.

Normas de transcripción

El documento se ha transcrito de forma modernizada, colocando la ortografía bajo parámetros actuales. Los topónimos también se modernizaron.

\section{Referencia del documento}

Real Biblioteca del Palacio Real de Madrid, "Visita eclesiástica hecha en 1765 / por Francisco Javier Fabián y Fuero, obispo de Puebla de los Ángeles, a algunos curatos de su diócesis: 1765”, Miscelánea de Manuel José Ayala, Ms. 2836, f. 1r-9v.

\section{[Portada]}

Visita ECLESIÁstica QUE EN EL AÑO DE $17[\dot{i} ?]^{19}$ hizo el ilustrísimo SeÑor obispo de la PUebla de los ÁNGeles DE ALGUNOS CURATOS DE SU DIÓCESIS; ESTADO QUE TENÍAN SUS PARROQUIAS Y PROVIDENCIAS QUE DIO PARA EL ALIVIO DE LOS MISERABLES INDIOS

\section{[f. 1] Señor}

Luego que entré en posesión de este obispado, que fue a últimos de junio del año pasado de 1765 me fue indispensable el detenerme algún tiempo en esta capital, así para dar las providencias que juzgué convenientes para

${ }^{18}$ Gracias al doctor Carlos Paredes Martínez es que pude tener acceso a éste en fotocopias que él obtuvo en alguna de sus jornadas de trabajo en esos repositorios de información.

${ }^{19}$ En la portada de las actas de visita pastoral no se asentó el año completo. 
el mejor gobierno de esta diócesis, como para enterarme de las circunstancias de su dirección, y proveer en concurso los curatos que hallé vacantes, y evacuados estos asuntos di principio a la visita eclesiástica de este obispado en 27 de diciembre del mismo año, lo que en cumplimiento de mi obligación participo a vuestra Majestad exponiendo sucintamente, y por su orden, los curatos que tengo visitados, y el estado en que encontré a cada uno, y empezando por el primero, que es el que sigue.

\section{Totimehuacan}

Dista este pueblo de la capital una legua, y habiendo llegado a él en dicho día como a las ocho de la mañana, oí la misa conventual que cantó su cura propio, y hecha la plática de visita se cantaron los responsos en la forma que previene el Pontificial Romano; después visité la iglesia, cuya fábrica es de bóveda, y está ya bastantemente deteriorada, y muy pobre de ornamentos; tiene este curato dos pueblos de visita que son San Andrés Azu[f. 1v]miatla, y San Pedro Tecola, distante el que más dos leguas de la cabeza; sus iglesias, cubiertas de zacate o heno, y apenas tienen lo preciso para celebrar una misa, porque la miseria y desdicha en que se hallan aquellos naturales no les deja arbitrio para surtirlas de lo necesario; hay en dicha cabecera un convento de recolección de religiosos de san Francisco, y aunque es corta en número su comunidad, que no pasa de 16 individuos, es mucho el provecho espiritual que con su predicación, y aplicación, al confesonario experimenta aquella feligresía: el número de sus familias llega a 460 de indios, con más algunas otras de españoles, y pardos, que hay en tres haciendas que se hallan en el término de aquel partido, que es del idioma mexicano.

\section{Huehuetlán}

Este curato, que es también del idioma mexicano, dista del antecedente ocho leguas, y dando principio a su visita en la misma forma que en el curato de arriba, que es igualmente la que practiqué en todos los demás curatos, hallé su iglesia de bóveda pero toda sumamente maltratada, y con la falta de muchas cosas que son indispensables para la celebración de los divinos oficios; y sin embargo de que mandé que todo se reparara en cuan- 
to fuera posible, significando pormenor [f. 2] las cosas que se debían reformar, y hacer de nuevo, se ha podido componer poco hasta ahora por falta de facultades en sus naturales: tiene este curato cinco pueblos de visita que son San Juan Coatetelco, San Nicolás Huehuetlán, Santa Marta, Santa María Magdalena y Santa Ana Otzolotepec, cuyas iglesias son unas reducidas capillas cubiertas de zacate, y con igual necesidad de decencia que la que se halla en la cabecera; se compone esta feligresía de cerca de más de cuatro leguas, y de un camino muy fragoso que hay desde la citada cabecera a Santa Marta, mandé que en este pueblo pusiera el párroco un ministro de pie fijo para que con más facilidad pudiera administrar los santos sacramentos, e influir a los naturales conforme a lo dispuesto por varias cédulas reales.

\section{Huatlatlauca}

Dista del antecedente cuatro leguas: su iglesia es también de bóveda de muy buena fábrica, pero destituida casi en un todo aun de aquello que es necesario para la precisa decencia; sus altares sin el menor aseo, pues apenas se encontraba en alguno una mesa de manteles que no estuviera devorada, e indecente, y aunque todo esto pedía un remedio ejecutivo, no lo permite la pobreza de aquellos [f. 2v] naturales: se compone esta feligresía de cinco pueblos de visita que son San Juan Atzompa, Santo Tomás, San Pablo, San Miguel y Santa María, distantes menos de cuatro leguas de la cabecera, y sus iglesias con no menor indecencia que la parroquia: las familias de que se compone esta feligresía son 688 de indios sin que entre éstos haya españoles, y sólo se encuentran algunos mestizos y mulatos que sirven en dos ranchos, que en lo espiritual pertenecen a aquella feligresía que es del idioma mexicano.

\section{Zacapala}

Dista del antecedente seis leguas: las paredes de su iglesia son de adobes, y está sin embovedar, y tan pobre de ornamentos que si no hubiera yo dado algunos no se pudiera decir misa sin la mayor indecencia: entre toda su feligresía componen poco más de 700 familias, y tiene por pueblos de visita los de Santa María, Santa Catarina, San Mateo y San Pedro, distantes 
los primeros de la cabecera algo más de dos leguas de un camino muy penoso, e intransitable por la noche, en cuya atención, y a la de ser estos dos pueblos del idioma puramente mixteco, quedando aun el curato de la lengua chocha, y mexicana, hice se practicaran las diligencias correspondientes para separarlos de la cabecera antigua y se ha hecho ya su división conforme a las leyes [f. 3] del Patronato Real erigiéndose en nueva parroquia el referido pueblo de Santa María con el anexo de Santa Catarina, que entre uno y otro componen cerca de 400 familias, y han puesto aquellos naturales su nueva parroquia con la decencia que les ha sido posible.

\section{Piaxtla}

Dista del antecedente doce leguas: su iglesia toda de bóveda, y de una decente fábrica, y medianamente surtida de ornamentos; del mismo modo se halla, y aún con alguna ventaja la del pueblo de Chinantla que está contiguo al citado de Piaxtla; y sus indios son de los más capaces que he tratado, muy devotos, y dedicados al culto divino: tenía este curato por pueblos de visita a los de San Martín Cuautitlán, Santa Catarina Tlaxcuapan, San Pedro Tecomatlán, San Miguel Tehuitzingo, Tuzantlán y Texalpan, distantes algunos más de seis leguas de la cabecera, y entre todos componían una feligresía de más de 900 familias de indios, además de otras muchas de españoles, mulatos y mestizos que viven en la cabecera, y en las haciendas, y ranchos de aquel partido; y por qué los naturales lograran con más facilidad su instrucción, y el pasto espiritual de sus almas, hice dividir este curato, y con consentimiento del virrey de esta [f. 3v] Nueva España se han erecto dos nuevas parroquias, que la una es el expresado San Miguel Tehuitzingo, en cuyo pueblo han hecho los indios una iglesia muy decente, y la han puesto con los ornamentos y utensilios precisos, agregándose a este curato nuevo los pueblos de Tuzantlán y Texalpan; la otra nueva parroquia se nombra San Pedro Tecomatlán, con el agregado del pueblo Ilamacingo y de algunos ranchos, y así en estas parroquias como en la antigua ha quedado congrua suficiente para sus respectivos párrocos, y ministros, y muy competente número de familias, habiendo compuesto las del referido pueblo de Tecomatlán medianamente su iglesia: los tres curatos referidos, y los demás que siguen son todos del idioma mexicano. 
Xicotlán

Dista este curato del antecedente diez leguas: la iglesia parroquial es toda de bóveda, y está con la correspondiente decencia: los pueblos de su visita son los de Chila, Ocotlán, Tlaltepexi, Xixingo, Acaxtlahuacán, Coacalco, Ixcamilpa y Tulcingo, cuyas iglesias a excepción de la de Chila, que está medianamente adornada por el afán y cuidado con que en esto se han esmerado los indios, se hallan con mucha indecencia, porque [f. 4] además de ser corto el número de las familias de que se compone cada uno de dichos pueblos, están con la mayor desdicha y miseria sin arbitrio aun para ganar su manutención, que no puede ser más escasa; tiene esta feligresía 520 familias de indios, y para su mejor administración dé providencia para que en el citado pueblo de Coacalco, que es el que más dista de la cabecera, y desde donde con más facilidad puede ser asistido el de Ixcamilpa, pusiese el cura un ministro que tuviera allí su residencia.

\section{Xochihuehuetlán}

Dista del antecedente seis leguas; su iglesia de unas paredes muy débiles, cubierta de zacate, y sin la precisa decencia; en la misma conformidad se hallan las de los pueblos de su visita que son Comitlipa, Tepetlapa, Cacalutla, Jilotepec, Tetitlán y Xihuitlipa, todo por la infelicidad en que viven aquellos pobres indios, mayormente los de la cabecera, pues por no tener para surtir la lámpara del Divísimo aun del aceite que se hace en esta tierra, de una hierba que llaman higuerilla, que no es caro, habían estado muchas veces, u temporadas sin santísimo sacramento, y a esto di la correspondiente providencia sin gravar en cosa alguna a los indios, y me persuado a que al presente no experimentarán semejante desconsuelo; las familias de [f. $4 \mathrm{v}$ ] que se compone esta feligresía son 420 de indios con muy pocas de españoles, y mulatos. En este curato me detuve más de un mes a causa de unas tercianas ${ }^{20}$ que me acontecieron, de cuyo accidente enfermaron también algunos de mi familia, y así por esto como porque me estrechaba ya el tiempo de semana santa para consagrar los santos óleos, pasé aun sin

${ }^{20}$ Terciana: La calentura que responde a tercero día, (c) lat. febris tertiana. Sebastián de Covarruvias Horozco, Tesoro de la lengua castellana o española (Pamplona: Universidad de Navarra; Madrid: Iberoamericana; Frankfurt: Vervuert; Madrid: Real Academia Española, Centro para la Edición de Clásicos Españoles, 2006), 1466. 
acabar de convalecer al pueblo de Chilapa por los de Huamuxtitlán, Cualac, Olinalá y Ahuacuotzingo, dando en ellos las providencias que más urgían. Es el de Chilapa entre los de aquella parte el lugar donde consideraba la mejor proporción para el asunto de los santos óleos; dista este pueblo del de Xochihuehuetlán más de veinte leguas, y de la Puebla más de sesenta hacia la costa del Mar del Sur; se compone de más de 900 familias, de españoles, mulatos y de otras castas que no son indios, y de éstos llega casi a 700 familias. La fábrica de su iglesia es de adobes; su techo de vigas y tablas, y cubierta de teja: está decentemente adornada así en sus altares como en lo demás que es necesario para la celebración de los divinos oficios; le han quedado sólo tres pueblos de visita que son Santa Catalina Calmecatitlán, San Guillermo Atzacoalo[f. 5]yan, y San Agustín Ayahualulco, porque aunque tenía también el de San Jerónimo Palantla hice que de éste, y de los de Ayahualtempa y Hueycantenango pertenecientes al curato de Atlixtac, y distantes de su cabecera cerca de once leguas, se formará conforme a las leyes del Real Patronato la correspondiente división, y se ha erecto en nueva parroquia el citado pueblo de Ayahualtempa desde donde con la mayor facilidad son administrados sus anexos, beneficio que antes no podían conseguir por las considerables distancias en que se hallaban de las cabeceras antiguas a que antes estaban sujetos, y concluida la visita del referido curato de Chilapa pasé al de

\section{Zitlala}

Dista del antecedente dos leguas: su iglesia es de bóveda, y de una fábrica muy buena, pero destituida de ornamentos, y no encontrando en ella santísimo por no haber facultades en los indios, ni dotación para la asistencia de la lámpara, di la providencia que tuve por más conveniente, y oportuna, y quedó su Majestad depositado en el sagrario antes de salir yo de aquel curato cuya visita está reducida a un pueblo solo nombrado San Juan Acatlán, distante poco más de una lengua de la cabecera, y su iglesia en igual [f. 5v] desamparo que la parroquia: toda esta feligresía entrando algunos ranchos que pertenecen a ella en lo espiritual se compone de 475 familias de indios con muy pocas personas de otras mezclas. 


\section{Tlalcozotitlán}

Dista del antecedente ocho leguas, y tiene cinco pueblos de visita que son el de Temalac, Copalillo, Oxtotlán, Mezquitlán y Papalutla; sus iglesias todas de adobes y cubiertas de zacate, excepto la de Temalac que es de bóveda, y aunque de muy corta capacidad, es proporcionada al vecindario: poco antes de llegar yo a este curato se quemó la iglesia de Copalillo sin haberse podido reservar cosa alguna de sus ornamentos; di los precisos para celebrar el santo sacrificio de la misa, e hice bendecir una capillita de las que los indios llaman Santo Cale, o santa Casa, adornada muy pobremente, y en ella se está diciendo misa hasta que los naturales consigan el poder hacer de nuevo su iglesia; tiene esta feligresía cerca de 400 familias de indios, y sin embargo de que son todos extremadamente pobres mantienen para su administración un cura, y un ministro de doctrina.

\section{Jolalpan}

Dista del curato antecedente ocho leguas. La [f. 6] iglesia es de bóveda muy capaz, pero su fábrica amenazando ruina, y con poca decencia en sus altares, y ornamentos; mas espero que con las providencias que se dieron, y ayudando sus naturales con lo que sufran sus fuerzas quede prontamente reparada: además de la parroquia hay otra iglesia que es (el) del barrio de Santa Ana, y de la misma fábrica, pero medianamente decente, y en ella se estaba haciendo un retablo mayor a devoción de los pobres indios que no dudo se habrá concluido ya enteramente, y habrá quedado con mayor aseo dicha iglesia: tiene este curato dos pueblos de visita que son el de Mitepec, y Teutla, y algunos ranchos, y haciendas que entre todos componen como 400 familias de indios, y algunas otras de españoles, mulatos, y personas de todas mezclas; los de Mitepec, y Teutla distan muy poco entre sí, y algo más de cuatro leguas de la cabecera, por cuyo motivo hice se pusiera en uno de ellos un ministro, y hasta ahora se mantiene cuidando de dichos dos pueblos, cuyas iglesias son de adobes, y cubiertas de zacate, y con muy poca decencia en sus ornamentos. 


\section{Teotlalco}

Dista del antecedente seis leguas; tiene por pueblos de visita a los de Tzicatlán, Tzompahuacán, Cuauhyucan, y Tepetlapa, y toda su feligresía [f. 6v] se compone de 350 familias de indios, y como otras ocho, o diez de españoles, y mestizos que se hallan en dos ranchos que en lo espiritual pertenecen a este curato; su iglesia es de bóveda, pero muy pobre de ornamentos, y mucho más las de dichos pueblos de visita distantes algunos dos leguas de la cabecera.

\section{Huaquechula}

Dista del antecedente cinco leguas; su iglesia parroquial es de un cañón de bóveda, y está toda con la correspondiente decencia; tiene por pueblos de visita a los de San Juan Huiluco, Santiago Tetla, Santa María Xoyatla, y Santa Ana Coatepec poco distantes de la cabecera, con algunas haciendas, y ranchos que pertenecen en lo espiritual a aquella feligresía, cuyo número de familias excede de 600 de indios, y llega a 300 de españoles, mulatos y pardos; hay en dicho pueblo un convento de recolección de religiosos del patriarca san Francisco, quienes aplicados al púlpito y confesionario sirven de mucho provecho espiritual en aquel curato.

\section{Villa de Carrión}

Dista este curato del antecedente cuatro leguas y en él se hallan dos parroquias una de españoles y otra de indios; la fábrica de ésta muy antigua y arruinada; la de aquélla es de un cañón de bóveda, y adornada con la correspondiente de[f. 7]cencia así en sus capillas, y retablos como en todo lo demás que es necesario para el culto divino, se celebran en ella los divinos oficios con el mayor decoro, y gravedad, por haber allí además de dos párrocos para el servicio de aquella parroquia (que uno de ellos está con el título de vicario foráneo) más de treinta clérigos que unos como tenientes de cura, y otros sin esta calidad son útiles para la administración así en el recinto de la villa, como en más de veinte haciendas de labor que están en su territorio, y aunque en tiempos pasados han sido éstas muy abundantes en sus cosechas de granos que vendiéndose entonces a precios muy subidos 
adelantaron de tal suerte esta población en conveniencias que era una de las más ricas de este obispado, se halla hoy en el mayor atraso porque a vista de la excesiva baja a que al presente ha venido el precio del trigo, y el de las demás semillas que no sufraga con mucho para costear los precisos gastos de las sementeras, y cosechas, y son pocos los labradores que han quedado; y en medio de que permanecen las haciendas, una se hallan concursadas, y otras sin haber facultades en sus dueños para cultivarlas, ni quien se atreva a tomarlas en arrendamiento por la acreditada experiencia de que aún sin esta pensión pierden no poco los mismos dueños que [f. $7 \mathrm{v}]$ las siembran.

Tiene esta feligresía más de 189 [ $\dot{z}^{\text {? }] ~ f a m i l i a s ~ d e ~ e s p a n ̃ o l e s, ~}{ }^{21}$ y 350 de pardos, negros, y mulatos; hay tres conventos de religiosos, uno del sagrado orden de carmelitas descalzos, otro de calzados de Nuestra Señora de la Merced, y otro también de los religiosos calzados de San Agustín, con más un convento de religiosas de Santa Clara, cuyas rentas están casi perdidas; tiene también un hospital que ha estado a cargo de los religiosos de San Juan de Dios, y habiendo reconocido por las cuentas de su administración el menoscabo que habían padecido sus rentas, y el poco cuidado con que habían sido asistidos los enfermos por los últimos religiosos, les removí de dicha administración, dejándola a la dirección, y cuidado de los referidos párrocos por ahora, y hasta tanto que se pongan religiosos que con celo, y amor asistan a los enfermos, y cuiden de las pocas rentas que tiene dicho hospital: en él se hallan comúnmente doce, o catorce enfermos, no porque no haya más necesitados en aquella villa, sino porque sus fondos no sufren más que este gasto administrado con toda economía. Dentro de la misma villa hay otra iglesia muy decente dedicada a san Félix Mártir, patrón de aquella vecindad, y sirve de mucho [f. 8] provecho espiritual a los barrios que le están contiguos porque en ella hay un capellán expuesto: se celebran diariamente algunas misas por devoción de muchos presbíteros al glorioso patrón; hay mucha frecuencia de sacramentos, y abundante pasto para las almas. En la citada villa no pude menos de detenerme bastante tiempo así para la visita de iglesias de testamentos, y capellanías, como para varios asuntos que ocurrieron muy propios de la visita eclesiástica; y llamado al fin de cosas del oficio pasé al numeroso pueblo de Orizaba distante de la Villa de Carrión

${ }^{21}$ Es conveniente hacer la anotación de que en el documento la grafía que representa al número de familias de españoles no es muy clara, por lo cual hemos colocado corchetes y signo de interrogación. 
Valle de Atlixco, más de treinta leguas, y compuesto de 1390 familias de españoles; mestizos, y demás personas de otras mezclas más de 400 de indios, y de cuatro pueblos de visita que son barrio nuevo, Zoquitlán, Ixhuatlán, e Ixhuatlancillo: visité la iglesia de la cabecera, y puse los decretos necesarios para el buen gobierno de aquel pueblo, y sus anexos; pero estrechado ya del tiempo, y de los negocios que pedían mi asistencia en esta capital, me fue preciso el restituirme a ella, habiendo administrado en toda la visita la confirmación a cuantos necesitaban de este santo sacramento. Estos son los curatos que he podido visi[f. 8v]tar hasta ahora sin que por el trabajo que ocasiona esta tarea haya permitido que el secretario, y demás oficiales de visita llevaran derechos algunos, ni menos la más leve gratificación; en todos he procurado que conforme a la extensión de sus feligresías, $\mathrm{y}$ los productos de las obvenciones, haya los ministros necesarios inteligentes en los idiomas que respectivamente se hablan en cada una de las referidas doctrinas: encontré en el discurso de la visita algunas cofradías, cuyos caudales de ciento o doscientos pesos el que más, han perdido cuantos han sido mayordomos de ellas, porque precisados de su pobreza los mayordomos tomaban, y gastaban los principales con la pensión de hacer la fiesta titular, pagar entre año la limosna de algunas misas, la cera, y otros gastos que todo por lo común no bajaba de 70 u 80 pesos, y de entregar por entero cumplido el año, el principal, sin haber percibido más que éste para los gastos expresados, y hasta que lo entregaban los volvían a dejar mayordomos para hacer cada año los mismos gastos, y así quedaban destruidos; viendo esta iniquidad en algunos pueblos di la correspondiente providencia de extinguir semejantes cofradías. He prohibido el servicio personal [f. 9] y otras contribuciones con que en los más de los citados curatos se hallaban grabados los naturales por sus curas, y he mandado así a éstos como a sus ministros de doctrina se arreglen en un todo al arancel que formó el ilustrísimo don Manuel Fernández de Santa Cruz, mi antecesor, y aprobó esta Real Audiencia, y repetidas veces está mandado observar en esta diócesis por varias cédulas de vuestra majestad. Finalmente, señor, he dado cuantas providencias han estado en mi arbitrio, y he juzgado convenientes, y oportunas para el alivio espiritual, y temporal de estos pobres vasallos de vuestra majestad, y particularmente de los miserables indios, tan justamente recomendados por la real piedad, porque verdaderamente son, entre todos, los que más necesitan protección, y socorro, y hablando con la verdad que es debida a vuestra augusta persona no he visto en toda la cordillera que he andado otra cosa que escuadrones numerosos de pobres desvalidos, y tanto más necesi- 
tados cuanto más distante de quien pueda socorrerles en aquellas desdichadas poblaciones; a vista de esta tan verídica como lastimosa desolación, no pude menos de recargarme con un nuevo empeño a fin de remediar en cuanto me fuera posible tantas, y tan crecidas miserias, y [f. 9v] aunque en parte lograba este consuelo me afligía al mismo tiempo el ver clamar a otros pobres sin poderles aliviar. Dios guarde a la cesárea real persona de vuestra majestad muchos años como hemos menester: Puebla de los Ángeles, y junio 27 del 76. ${ }^{22}$ Señor. El obispo de la Puebla de los Ángeles.

\section{FuENTES}

Archivos

Archivo Histórico Casa de Morelos

Diocesano, Gobierno, Visitas, Informes, 1780, caja 506, exp. 80, f. s/n.

Diocesano, Gobierno, Visitas, caja 500, exp. 50 y 53, f. s/n.

\section{Bibliografía}

Aguirre Salvador, Rodolfo, coord. Visitas pastorales del arzobispado de México, 17151722, 2 v. V. I. México: Universidad Nacional Autónoma de México, Instituto de Investigaciones sobre la Universidad y la Educación, 2016 (La Real Universidad de México, xxxv).

B. Buitrón, Juan. Apuntes para servir a la historia del arzobispado de Morelia. México: Imprenta Aldina, 1948.

Cedeño Peguero, María Guadalupe, y Silvia Montes de Oca Mireles. "Visitas episcopales en Michoacán e historia social purépecoha", en Los occidentes de México (siglos XVI-XIX). El archivo, instrumento y vida de la investigación histórica. Compilación de Celina Guadalupe Becerra J., 149-174. México: Centro de Estudios Mexicanos y Centroamericanos; Guadalajara: Universidad de Guadalajara; Zamora: El Colegio de Michoacán; Zacatecas: Doctorado en Historia INAH-UAZ; Morelia: Archivo Histórico del Municipio de Morelia; Zapopan: El

${ }^{22}$ Francisco Fabián y Fuero fue obispo de Puebla de 1765 a 1773, por lo que consideramos que esta fecha consignada al final de las actas de visita pastoral tiene un error, ya que en 1776 Victoriano López Gonzalo ocupaba la silla episcopal en Puebla y Fuero se desempeñaba como arzobispo de Valencia, en España. 
Colegio de Jalisco; México: Centro de Investigaciones y Estudios Superiores en Antropología Social-México, 1997.

Covarruvias Horozco, Sebastián de. Tesoro de la lengua castellana o española. Pamplona: Universidad de Navarra; Madrid: Iberoamericana-Vervuert; Madrid: Real Academia Española, Centro para la Edición de Clásicos Españoles, 2006.

Cruz Peralta, Clemente. "Entre la disciplina eclesiástica y la reforma de las costumbres. Visitas pastorales de Francisco Antonio Lorenzana a la arquidiócesis de México, 1767-1769.” Tesis de maestría, Universidad Nacional Autónoma de México, Facultad de Filosofía y Letras, Instituto de Investigaciones Históricas, 2016.

Cuevas, Mariano. Historia de la Iglesia en México, t. I. México: Imprenta del Asilo "Patricio Sanz", 1921.

Garza Martínez, Valentina, y Juan Manuel Pérez Zevallos. Las visitas pastorales de Mazapil, 1572-1856. México: Centro de Investigaciones y Estudios Superiores en Antropología Social; Mazapil, Zacatecas: Municipio de Mazapil; San Luis Potosí: Archivo Histórico del Estado de San Luis Potosí “Lic. Antonio Rocha Cordero"; México: Editorial Letra Antigua; Zacatecas: Instituto Zacatecano de Cultura “Ramón López Velarde”, 2007.

Jaramillo Magaña, Juvenal. Hacia una Iglesia beligerante: la gestión episcopal de fray Antonio de San Miguel en Michoacán (1784-1804). Los proyectos ilustrados y las defensas canónicas. Zamora: El Colegio de Michoacán, 1996.

Luque Alcaide, Elisa. "Los concilios provinciales hispanoamericanos.” En Teología en América Latina. Volumen II/1. Escolástica barroca, Ilustración y preparación de la Independencia (1665-1810). Dirección de Josep-Ignasi Saranyana y coordinación de Carmen-José Alejos Grau, 423-523. Madrid: Iberoamericana; Frankfurt: Vervuert, 2005.

Manuscritos del Concilio Tercero Provincial Mexicano (1585). Edición, estudio introductorio, notas, versión paleográfica y traducción de textos latinos de Alberto Carrillo Cázares, primer tomo, v. I, Zamora: El Colegio de Michoacán; México: Universidad Pontificia de México, 2006.

Márquez Carrillo, Jesús. "Experiencia interior y política pastoral. El obispo Francisco Fabián y Fuero en Puebla 1765-1773." Graffylia. Revista de la Facultad de Filosofía y Letras, v. 2 (2003): 103-111.

Márquez Carrillo, Jesús. Política, Iglesia y modernidad en Puebla. Las ideas y proyectos reformistas del obispo Francisco Fabián y Fuero, 1765-1773. Primera edición digital. México: Benemérita Universidad Autónoma de Puebla, Facultad de Filosofía y Letras, 2017, http://www.filosofia.buap.mx (consulta: 2 de enero del 2018).

Mazín Gómez, Óscar. "Reorganización del clero secular novohispano en la segunda mitad del siglo Xviı..” Relaciones, v. x, n. 39 (1989), 69-86. 
Pérez Iturbe, Marco Antonio, y Berenise Bravo Rubio. "Hacia una geografía espiritual del arzobispado de México, la visita pastoral de José de Lanciego y Eguilaz de 1715.” En Doris Bieñko de Peralta y Berenise Bravo Rubio, coords., De sendas, brechas y atajos. Contexto y crítica de las fuentes eclesiásticas, siglos XVI-XVIII, 147-165. México: Consejo Nacional para la Cultura y las Artes, Escuela Nacional de Antropología e Historia, 2008.

Tavera Alfaro, Xavier, y Juvenal Jaramillo Magaña. Documentos para la historia de la ciudad de Valladolid de Michoacán. V. I. Morelia: LXXI Legislatura del H. Congreso de Michoacán, 2010.

Villaseñor y Sánchez, Joseph Antonio de, Theatro americano. Descripción general de los reynos y provincias de la Nueva España y sus jurisdicciones. México: Trillas, 1992.

Zahino Peñafort, Luisa. El cardenal Lorenzana y el IV Concilio Provincial Mexicano. México: Miguel Ángel Porrúa; México: Universidad Nacional Autónoma de México, Instituto de Investigaciones Jurídicas; Ciudad Real: Universidad de Castilla-La Mancha; Ciudad Real: Cortes de Castilla-La Mancha, 1999.

\section{SOBRE LA AUTORA}

Licenciada en Historia con mención honorífica por la Facultad de Historia de la Universidad Michoacana de San Nicolás de Hidalgo. Estudiante del doctorado en Historia del Centro de Estudios Históricos de El Colegio de Michoacán. Su línea de generación y aplicación del conocimiento es la historia cultural de la época colonial. Su publicación más reciente es "Visiones comparadas sobre los indios y sus lenguas, del arzobispado de México, obispado de Puebla y obispado de Michoacán, en el marco del IV Concilio Provincial Mexicano de 1771”, en Nelson Jofrak Rodríguez Cázarez y Juan Carlos Ruiz Guadalajara, coords., La monarquía hispánica en América. Estudios de caso (Homenaje a Bernardo García Martínez) (México: El Colegio de San Luis, en prensa). 